\section{Nocturnal airflow obstruction, histamine, and the autonomic central nervous system in children with allergic asthma}

\author{
W M C van Aalderen, D S Postma, G H Koëter, K Knol
}

\begin{abstract}
A study was carried out to investigate whether an imbalance in the autonomic nervous system or release of histamine, or both, is responsible for the nocturnal increase in airflow obstruction in asthmatic children. The study comprised 18 children with allergic asthma, nine with (group 1) and nine without (group 2) nocturnal airflow obstruction, and an age matched control group. All drugs were withheld for three days before and during the study. On day 4 each child was admitted to hospital and a series of measurements was made every four hours for 24 hours. These included measurements of the forced expiratory volume in one second $\left(F E V_{1}\right)$, heart rate and sinus arrhythmia gap from an electrocardiogram (an indirect measure of parasympathetic activity) and urine sampling for determination of catecholamine and $N^{\tau}$-methylhistamine concentrations (measures of sympathetic activity and histamine release respectively). Urinary $N^{2}$-methylhistamine excretion was significantly higher over the 24 hours in children in group 1 than in children in group 2, and overnight values were also significantly higher in children in group 1 than those in group 2. Mean (SEM) values ( $\mu \mathrm{mol} / \mathrm{mol}$ creatinine) were $154.6(11 \cdot 2)$ in group 1 and 110 $(11 \cdot 2)$ in group 2 for $2400-0400$ hours samples and 139.2 (13.1) and 101.2 (10.6) 0400-0800 hours samples. There was no evidence of decreased sympathetic or increased parasympathetic activity in association with the nocturnal airflow obstruction; noradrenaline concentrations were increased in group 1. These observations indicate that nocturnal airflow obstruction is associated with increased release of histamine overnight.
\end{abstract} Department of
Paediatrics W M C van Aalderen K Knol

Department of Pulmonary Medicine D S Postma G H Koëter

University Hospital, 9713 EZ Groningen, The Netherlands

Reprint requests to: Dr van Aalderen

Accepted 28 January 1991 common symptoms in adults and children with asthma and are associated with obstruction of airflow. ${ }^{12}$ The increased nocturnal airflow obstruction is thought to be the result of an amplification of the normal circadian rhythm of pulmonary function. ${ }^{3}$

One of the causes of nocturnal and early morning dyspnoea might be an imbalance in the autonomic regulation of bronchial smooth muscle. An increase in parasympathetic tone, mediated by the vagus nerve, would cause contraction of bronchial smooth muscle and increased mucus secretion. Circulating catecholamines cause bronchodilatation by stimulating the bronchial smooth muscle $\beta_{2}$ receptor adenylate cyclase complex. They can also inhibit release of mediators from different cell types, such as mast cells, and in this way may provide additional protection against airflow obstruction. ${ }^{4}$

Inflammation may also play an important part in nocturnal airflow obstruction, as suggested by Kraan et al, ${ }^{5}$ who reported that four weeks of treatment with the inhaled corticosteroid budesonide resulted in decreased diurnal variation in peak expiratory flow and in bronchial responsiveness in young adults with asthma.

In the present study, which supplements previous work, ${ }^{6}$ we investigated circadian variations in airflow obstruction, the balance of the autonomic nervous system, and histamine excretion in children with allergic asthma with and without nocturnal airflow obstruction and compared them with measurements in healthy children matched for age.

\section{Methods}

PATIENTS

Asthmatic children from the paediatric asthma outpatient clinic selected to participate in the study were asked to stop taking all prophylactic drugs and bronchodilators for three days before admission. The children were assigned to two groups on the basis of peak expiratory flow measurements (best of three) performed every four hours during three days at home. Selection criteria were as follows:

1 Peak expiratory flow amplitude measured at home on three consecutive days (amplitude is defined as the difference between the highest and lowest peak expiratory flow value measured over 24 hours expressed as a percentage of the highest value): children were assigned to group 1 if they had an amplitude $\geqslant 20 \%$; the children assigned to group 2 were matched for age with those in group 1 but had a peak expiratory flow amplitude $<15 \%$. stimuli.

3 A daytime forced expiratory volume in one second $\left(\mathrm{FEV}_{1}\right)>70 \%$ of predicted value (FEV $1 \%$ predicted).

4 Increased serum total IgE concentration (normal values were taken from the paper exposure to allergens and non-allergic 
by $\mathrm{Kjellman}^{7}$ ) and a positive intracutaneous skin test response (weal $>5 \mathrm{~mm}$ ) to house dust mite extract (Diephuis laboratories, The Netherlands).

5 A provocation concentration of inhaled histamine of $<16 \mathrm{mg} / \mathrm{ml}$-that is, the concentration causing a fall in baseline $\mathrm{FEV}_{1}$ of $\geqslant 20 \%\left(\mathrm{PC}_{20}\right)$.

In order to have an otherwise homogeneous group of patients the only difference in selection criteria between the two patient groups was the difference in peak expiratory flow amplitude values. Symptoms of asthma were well controlled by maintenance drugs. No child had had a respiratory tract infection in the three months before the study and none had taken oral corticosteroids for at least six months.

Nine healthy children matched for age with the children in the patient groups took part in the study. These control subjects were not taking drugs, and had no history of respiratory complaints. They had normal spirometric values, normal blood eosinophil counts, and negative skin test responses to house dust mite extract. None of them had a $\mathrm{PC}_{20}$ histamine $<16 \mathrm{mg} / \mathrm{ml}$.

Informed consent was obtained from the children and their parents. The study protocol was approved by the hospital's ethical committee.

\section{STUDY DESIGN}

All drugs were withheld for three days before and during the study. The study was performed during the three months from September to November in 1986 and 1987. In hospital meals and sleeping occurred at fixed times. Before each set of measurements was taken, the children rested in the supine position for 20 children rested in the supine position for 20 minutes. On day 4 (the day of admission) measurements were performed every four hours for 24 hours (at $0800,1200,1600,2000$, 2400, 0400 hours). Each set of measurements entailed, in chronological order, electrocardiography, measurement of $\mathrm{FEV}_{1}$, and collecting urine samples. Urine samples were collected over every four hour period, starting at 0800 hours, and used for determining free catecholamine and $N^{t}$-methylhistamine concentrations.

\section{METHODS}

Measurements of $\mathrm{FEV}_{1}$ were carried out with a water sealed spirometer (Lode, The Netherlands) and expressed as a percentage of the predicted value. The best of three efforts was then used. Normal values were taken as those reported by Zapletal et al. ${ }^{8}$

\section{Histamine inhalation test}

Histamine acid phosphate, ranging in doubling concentrations from $0.03 \mathrm{mg} / \mathrm{ml}$ to $16 \mathrm{mg} / \mathrm{ml}$, was inhaled for two minutes from a DeVillbiss 646 nebuliser (output $0.13 \mathrm{ml} / \mathrm{min}$ ). The $\mathrm{PC}_{20}$ was calculated by interpolation from the logarithmic dose-response curve. ${ }^{6}$

\section{Noradrenaline and adrenaline assays}

Urine samples for determination of free catecholamine concentrations were collected in polyethylene bottles containing $50 \mathrm{mg}$ of sodium metabisulphite as an antioxidant. After the collection period (four hours) hydrochloric acid $(0 \cdot 1 \mathrm{M})$ was added to reduce the $\mathrm{pH}$ to about 3. Samples were stored at $-20^{\circ} \mathrm{C}$ until analysis. Analysis was by high performance liquid chromatography with electrochemical detection, as described by Westerink et al, ${ }^{9}$ with the addition of dihydroxybenzylamine as

Table 1 Clinical data on patients in group 1 (peak expiratory flow amplitude $\geqslant 20 \%$ ) and group $2(<15 \%)$

\begin{tabular}{|c|c|c|c|c|c|}
\hline Patient No & Sex & Age (years) & $F E V, \%$ pred $^{\star}$ & $\begin{array}{l}P C_{20} \\
\text { histamine }(\mathrm{mg} / \mathrm{ml}) \dagger\end{array}$ & Drugs being taken $\ddagger$ \\
\hline \multicolumn{6}{|l|}{ Group 1} \\
\hline 1 & $\mathbf{M}$ & 9 & 72 & $2 \cdot 00$ & Inhaled corticosteroid \\
\hline 2 & $\mathbf{M}$ & 11 & 70 & 0.32 & Inhaled corticosteroid \\
\hline 3 & $\mathbf{M}$ & 13 & 75 & $2 \cdot 00$ & Inhaled corticosteroid \\
\hline 4 & $\mathbf{F}$ & 13 & 82 & $0 \cdot 37$ & Inhaled corticosteroid \\
\hline 5 & $\mathbf{F}$ & 13 & 79 & $0 \cdot 78$ & $\begin{array}{l}\text { Sodium cromoglycate } \\
\text { and theophylline }\end{array}$ \\
\hline 6 & $\mathbf{M}$ & 10 & 101 & $0 \cdot 26$ & Inhaled corticosteroid \\
\hline 7 & $\mathbf{M}$ & 12 & 75 & 1.62 & Inhaled corticosteroid \\
\hline 8 & $\mathbf{M}$ & 14 & 84 & $2 \cdot 75$ & Sodium cromoglycate \\
\hline 9 & $\mathbf{M}$ & 10 & 75 & $0 \cdot 37$ & Sodium cromoglycate \\
\hline \multicolumn{2}{|l|}{ Mean (SEM) } & $11.7(0.6)$ & $78 \cdot 1(3 \cdot 4)$ & $0.82 \S$ & \\
\hline \multicolumn{6}{|l|}{ Group 2} \\
\hline 1 & $\mathbf{M}$ & 8 & 77 & 0.88 & Inhaled corticosteroid \\
\hline 2 & $\mathbf{M}$ & 10 & 97 & 1.52 & Sodium cromoglycate \\
\hline 3 & $\mathbf{M}$ & 12 & 80 & 1.83 & Sodium cromoglycate \\
\hline 4 & $\mathbf{F}$ & 13 & 90 & $1 \cdot 70$ & Sodium cromoglycate \\
\hline 5 & $\mathbf{F}$ & 12 & 90 & 0.41 & Inhaled corticosteroid \\
\hline 6 & $\mathbf{F}$ & 10 & 97 & $6 \cdot 15$ & Sodium cromoglycate \\
\hline 7 & $\mathbf{M}$ & 13 & 65 & $2 \cdot 00$ & Inhaled corticosteroid \\
\hline 8 & $\mathbf{M}$ & 14 & 95 & 3.65 & Beta $_{2}$ adrenergic drugs \\
\hline 9 & $\mathbf{F}$ & 10 & 100 & $4 \cdot 37$ & Sodium cromoglycate \\
\hline \multicolumn{2}{|l|}{ Mean (SEM) } & $11.3(0.6)$ & $88.5(3.9)$ & $1.91 \S$ & \\
\hline
\end{tabular}

*Values obtained at 0800 hours on day 4.

+Values obtained at 0800 hours on day 6 .

tAll patients occasionally inhaled beta ${ }_{2}$ adrenergic drugs; patient 8, group 2, took them regularly.

$\S$ Geometric mean values were not significantly different. 
FEV $1 \%$ pred
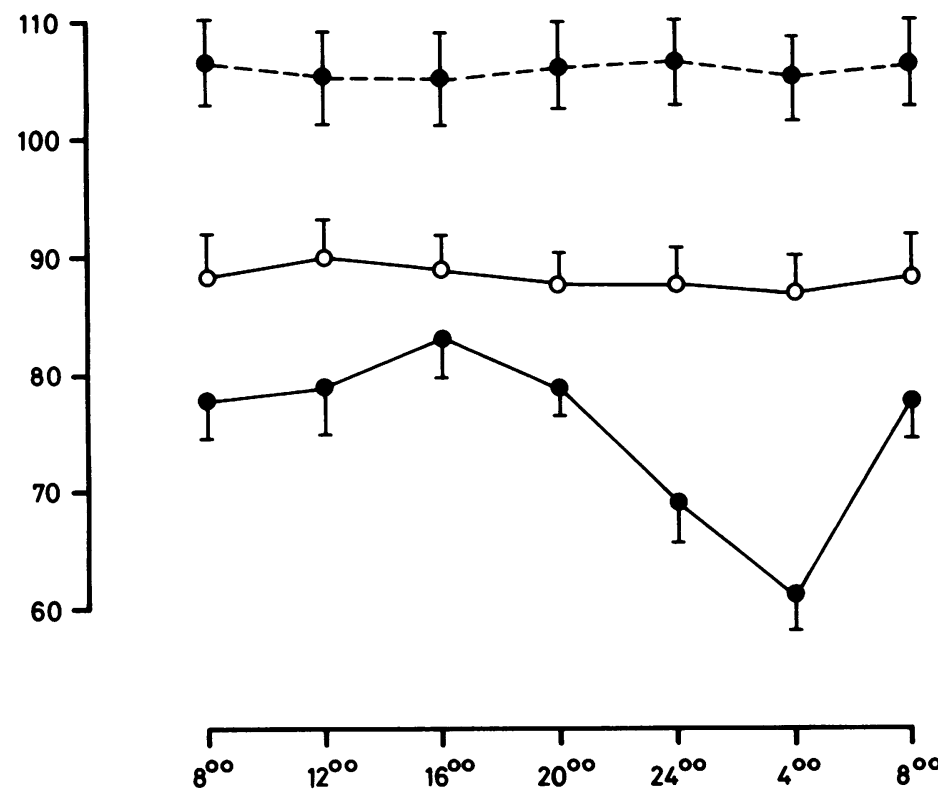

Clock time

Figure 1 Mean (SEM) percentage predicted FEV, for day 4 in group 1 (- - ), group 2 (- - ), and control group (---०--).

an internal standard. This procedure resulted in a coefficient of variation of $2 \%$ for noradrenaline and of $4.6 \%$ for adrenaline $(n=10)$.

\section{$N^{\tau}$-methylhistamine assay}

The concentration of $N^{\tau}$-methylhistamine, an excretion product of endogenously produced histamine, was determined in the same urine samples by isotope dilution mass spectrometry. ${ }^{1011}$ On the day before the study and during the study the participants avoided food known or suspected to contain histamine. All samples from each subject were analysed together, a blinded procedure being used.

\section{Electrocardiography}

Electrocardiography (with lead II) was performed and recorded on a Cardiostat 701 (Siemens, Germany). To measure vagal activity indirectly the electrocardiogram was recorded for 60 seconds. Heart beat frequency was determined with the children semirecumbent and breathing deeply at a rate of 10 breaths per minute modified from the method of Kallenbach et al. ${ }^{12}$ The duration of each respiratory cycle was six seconds, with equal time for inspiration and expiration. The seconds were counted aloud by one of the investigators, who ensured that breathing was continuous. Forced breaths and maximum respiratory manoeuvres were avoided because of the possibility of provoking bronchospasm in the asthmatic children. ${ }^{13}$ The longest and shortest $\mathbf{R}-\mathbf{R}$ intervals were selected from each electrocardiogram strip and measured as beats per minute. The magnitude of the sinus arrhythmia gap was expressed as the mean difference between the maximum and minimum heart rate. ${ }^{14}$

\section{Analysis}

Comparison among the three groups for each set of measurements over 24 hours was carried out by one way analysis of variance (ANOVA). Obvious differences between the groups at any time point were compared by Student's unpaired $t$ test. Unless stated otherwise, all values are expressed as means (standard errors in parentheses).

\section{Results}

Nine children aged 8-15 years who fulfilled the selection criteria were selected for each of the patient groups. Table 1 gives their clinical details. Mean peak expiratory flow amplitude at home (mean of three 24 hour measurements) was $37.6(2 \cdot 1) \%$ for group 1 and $9.0(0 \cdot 7) \%$ for group 2.

\section{Pulmonary function measurements}

FEV 1 values in the three groups differed significantly $(F=106.3$, df $=2, p<0.001)$, values in the control group being significantly higher than those in group 2, and values in group 2 being significantly higher than those in group 1 (fig 1).

\section{Parasympathetic activity}

All three groups showed variation in heart rate over 24 hours, with the highest values occurring during the day and the lowest values at night. There was no variation over the 24 hours in values for the sinus arrhythmia gap (table 2 ). Heart rate and sinus arrhythmia gap values differed significantly among the three groups $(F=5.223, \mathrm{df}=2, \mathrm{p}=0.006$ and $\mathrm{F}=6.227$, $\mathrm{df}=2, \mathrm{p}=0.003$, respectively). Children in group 1 and control children had higher heart

Table 2 Mean (SEM) heart rate (beats/min) and sinus arrhythmia gap (beats/min) in children with nocturnal asthma (group 1), those without nocturnal asthma (group 2), and controls over 24 hours on day 4 of study

\begin{tabular}{|c|c|c|c|c|c|c|c|}
\hline & 0800 & 1200 & 1600 & 2000 & 2400 & 0400 & 0800 \\
\hline \multicolumn{8}{|l|}{ Heart rate ${ }^{\star}$} \\
\hline $\begin{array}{l}\text { Group } 1 \\
\text { Group } 2 \\
\text { Controls }\end{array}$ & $\begin{array}{ll}84 \cdot 9 & (4 \cdot 0) \\
79 \cdot 3 & (4 \cdot 4) \\
83 \cdot 2 & (4 \cdot 7)\end{array}$ & $\begin{array}{l}75 \cdot 8(2 \cdot 5) \\
71 \cdot 3(3 \cdot 4) \\
75 \cdot 6(2 \cdot 8)\end{array}$ & $\begin{array}{ll}82.4 & (3 \cdot 7) \\
73.8 & (3 \cdot 2) \\
78.3 & (2 \cdot 9)\end{array}$ & $\begin{array}{ll}90 \cdot 9 & (6 \cdot 1) \\
76 \cdot 0 & (3 \cdot 6) \\
81 \cdot 1 & (3 \cdot 6)\end{array}$ & $\begin{array}{l}76 \cdot 2(3 \cdot 9) \\
68 \cdot 5(2 \cdot 5) \\
75 \cdot 4(3 \cdot 7)\end{array}$ & $\begin{array}{ll}68 \cdot 7(2 \cdot 4) \\
69 \cdot 1(4 \cdot 0) \\
72 \cdot 7(3 \cdot 6)\end{array}$ & $\begin{array}{l}80.9(3.6) \\
74.6(4.3) \\
82.3(4.7)\end{array}$ \\
\hline \multicolumn{8}{|c|}{ Sinus arrhythmia gap $\dagger$} \\
\hline $\begin{array}{l}\text { Group 1 } \\
\text { Group } 2 \\
\text { Controls }\end{array}$ & $\begin{array}{l}21.3(2.4) \\
23.1(2.9) \\
19.5(1.4)\end{array}$ & $\begin{array}{ll}20 \cdot 5 & (2 \cdot 0) \\
24 \cdot 2 & (3.3) \\
22.7 & (1.9)\end{array}$ & $\begin{array}{l}19.8(1.6) \\
26.8(2.5) \\
20.9(1.9)\end{array}$ & $\begin{array}{l}17.0(2.4) \\
23.8(3.0) \\
20.9(1.9)\end{array}$ & $\begin{array}{l}16.9(2.4) \\
22.6(1.7) \\
19.8(1.7)\end{array}$ & $\begin{array}{ll}20 \cdot 5 & (2 \cdot 7) \\
22 \cdot 1(2 \cdot 1) \\
19 \cdot 3(1 \cdot 3)\end{array}$ & $\begin{array}{l}21.3(2.0) \\
23.7(1.9) \\
19.5(1.4)\end{array}$ \\
\hline
\end{tabular}

«ANOVA: $F=5 \cdot 223, \mathrm{df}=2, \mathrm{p}=0.006$

†ANOVA: $F=6 \cdot 227, \mathrm{df}=2, \mathrm{p}=0.003$ 


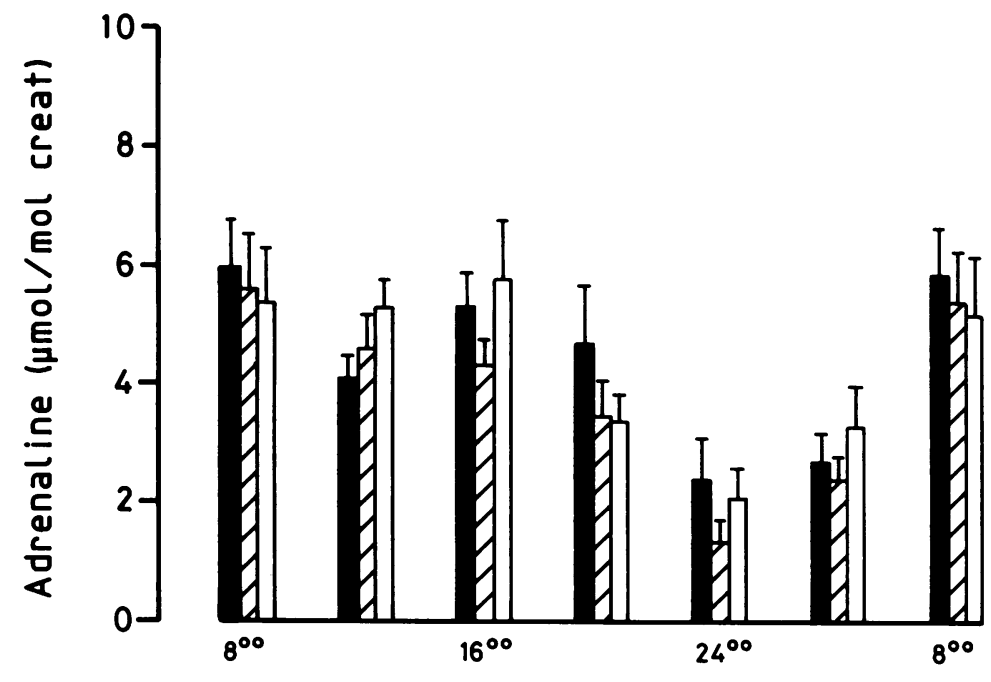

rates and lower sinus arrhythmia gap values than those in group 2.

\section{Sympathetic activity}

There were no significant differences in urinary adrenaline excretion among the three groups ( $p$ $>0.05$; fig 2 (top)), and the three groups showed a comparable fall in urinary adrenaline concentration during the night. There were, however, significant differences in noradrenaline excretion $(\mathrm{F}=9.110, \mathrm{df}=2, \mathrm{p}<0.001)$, which was higher in children in group ' 1 between 2000 and 0400 hours when compared with values in those in group 2 (values for 2000-2400 hours were 25.5 (2.6) and 19.1 (1.3) $\mu \mathrm{mol} / \mathrm{mol}$ creatinine in groups 1 and 2 , respectively ( $p<0.05$ ) and for $2400-0400$ hours were $19.1(1.4)$ and $11.9(1.0) \mu \mathrm{mol} / \mathrm{mol}$ creatinine $(\mathrm{p}$ $<0.01)$ ). Noradrenaline excretion was also higher in those in group 1 in the 2000-2400 hours sample than in controls $(17 \cdot 7(1 \cdot 6) \mu \mathrm{mol} /$ mol creatinine $(\mathrm{p}<0.05))$. There were no significant differences between the values in group 2 and in the control group at any time. No significant correlation between individual $\mathrm{FEV}_{1}$ values and urinary adrenaline concentrations was observed $(r=0.20$ and 0.02 for groups 1 and 2 respectively).

\section{Urinary $N^{\tau}$-methylhistamine}

$N^{\tau}$-methylhistamine excretion differed significantly among the groups $(\mathrm{p}<0.001)$, being higher in group 1 than in both group 2 and the control group. It increased overnight in group 1 but showed no variation over the 24 hours in the other two groups (fig 3). $N^{\tau}$-methylhistamine excretion was higher in group 1 between 2400 and 0800 hours than in group 2 (mean (SEM) values for 2400-0400 hours $154.6(11 \cdot 2)$ and $110(11 \cdot 2) \mu \mathrm{mol} / \mathrm{mol}$ creatinine for groups 1 and 2 respectively ( $p<0.02$ ), and for $0400-0800$ hours $139 \cdot 2(13 \cdot 1)$ and $101 \cdot 2$

Figure 2 Mean (SEM) urinary adrenaline concentration (top) and noradrenaline concentration (bottom) in group 1 (black bars), group 2 (striped bars), and the control group (open bars). Time refers to the start of the four hour collection period. $(10 \cdot 6) \mu \mathrm{mol} / \mathrm{mol}$ creatinine $(\mathrm{p}<0.05))$.

\section{Discussion}

In this study we compared results in asthmatic children with and without increased nocturnal airflow obstruction and an age matched control group of non-asthmatic subjects. Children with nocturnal bronchoconstriction had lower baseline $\mathrm{FEV}_{1}$ values, higher excretion of $N^{\tau}$ methylhistamine from 2400 to 0800 hours, and higher noradrenaline excretion from 2000 to 0800 hours. Adrenaline excretion was comparable in the three groups. There were no differences in heart rate and sinus arrhythmia gap values among the three groups and hence no evidence of any difference in parasympathetic activity.

The increased urinary concentration of $N^{\tau}-$ methylhistamine reflected release of histamine, presumably from the lung, in these patients. Increased histamine concentrations could, through irritant receptors in the larger airways, enhance vagal tone and indirectly cause an increase in airflow obstruction. As there was no evidence of increased cardiac vagal activity in either patient group during the day or night increased vagal activity is unlikely to explain

Figure 3 Mean (SEM) change in urinary $N^{\top}$-methylhistamine concentration in group 1 (black bars), group 2 (striped bars), and the control group (open bars). Time refers to start of the four hour collection period. 
nocturnal airflow obstruction. Our observations are consistent with the findings of Barnes et al, ${ }^{15}$ who observed an increase in plasma histamine concentration during the night. Postma et al ${ }^{16}$ observed a slight increase in $N^{t}$-methylhistamine excretion over 24 hours in nonallergic patients with chronic obstructive lung

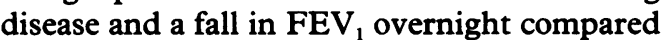
with matched controls, but no nocturnal increase. These observations suggest that, at least in chidren and adults with allergic asthma, histamine release contributes to nocturnal airflow obstruction. The release of histamine is probably due to inflammatory changes in the lung occurring at night. The possibility that release of mediators and inflammation may play a part in nocturnal asthma is supported by studies in which anti-inflammatory treatment showed improvement of nocturnal pulmonary function values and bronchial responsiveness. ${ }^{51718}$

The reason for the difference in $N^{\tau}$-methylhistamine excretion between the patient groups is not clear. The $\mathrm{FEV}_{1}$ values in group 1 were lower than those in the other two groups and the children in this group took more inhaled steroids than the asthmatic children in group 2, suggesting they had more severe asthma. This may explain the difference in $N^{\tau}$-methylhistamine excretion. The fall in adrenaline concentration overnight may have reduced the $\beta$ adrenergic protection of mast cells, ${ }^{4}$ and the ability of mast cells to release histamine in group 1 was greater than in the other children. ${ }^{19}$

Nocturnal and early morning dyspnoea in asthmatic patients is generally thought to be the result of an amplification of the normal circadian rhythm in airflow obstruction. ${ }^{3}$ This amplification may be due to autonomic imbalance, which has been mentioned as a cause of bronchial responsiveness. ${ }^{20}$ In our study noradrenaline excretion was higher over the 24 hours and overnight in children in group 1 than in those in the other two groups. These raised excretion concentrations were probably a result of the nocturnal bronchoconstriction. Our observations suggest that abnormalities in beta adrenergic control is not of major importance in nocturnal dyspnoea in asthmatic children.

Our data were consistent with those of Barnes et $a l^{15}$ in that a significant fall in adrenaline excretion overnight was observed in both asthmatic and normal subjects. In contrast with their study we observed no correlation between $\mathrm{FEV}_{1}$ values and urinary catecholamine concentrations at any time.

A nocturnal increase in parasympathetic activity is another possible cause of nocturnal airflow obstruction. Children in group 1 and the control subjects had a higher heart rate and lower sinus arrhythmia gap values than the children in group 2 . These observations do not support the hypothesis that increased parasympathetic activity is important in nocturnal airflow obstruction in children with asthma. As heart rate and sinus arrhythmia gap are indirect measures of parasympathetic activity our observations must be interpreted with caution. Failure to observe a change in cardiac vagal activity does not necessarily mean that vagal activity to bronchial smooth muscle is normal. Morrison et al found that intravenous atropine resulted in significant bronchodilatation and an increase in heart rate at 0400 and 1600 hours. $^{21}$ The decrease in heart rate and increase in sinus arrhythmia gap overnight seen by Postma et $a l^{16}$ and Kallenbach et al ${ }^{12}$ occurred at the same time as the nocturnal airflow obstruction. These observations suggest that parasympathetic activity to the bronchial tree may be reflected by cardiac measures.

The children in our study were woken every four hours, and sleep disruption may have influenced our observations. To investigate whether sleep disruption influenced the degree of nocturnal airflow obstruction Hetzel and Clark $^{22}$ and Caterall et $a^{23}$ compared peak expiratory flow values in asthmatic patients after intermittent awakening with values when the patients were kept awake until after the time at which the nocturnal fall in peak expiratory flow rate would have been expected (0300 to 0500 hours). They then slept until 0600 hours. The results of these studies are not conclusive. Disruption of sleep in our study may have caused a lesser degree of airflow obstruction overnight. This should, however, have affected children in all three groups in our study.

In conclusion, our results suggest that in children with more severe and unstable allergic asthma there is a tendency for urinary histamine secretion to be increased throughout the day and night, but particularly at night. This enhanced secretion may reflect increased inflammatory activity and release of mediators within the airways. Endogenous adrenaline was insufficient to prevent the increase in airflow obstruction overnight in asthmatic children.

We thank Mrs A Teuben-Tanja for performing part of the measurements; L Martijn, who did the drawings; F G Sluiter for translating the manuscript; and J Wempe for help with the analysis of the results. The adrenaline and noradrenaline urinary concentrations were determined by $\mathbf{H}$ Breukelman, central clinical chemical laboratory of the University Hospital of Groningen. The $N$-methylhistamine urinary concentrations were determined by $\mathrm{E}$ Oosting, Bergschot Centre for Research, Breda, The Netherlands. The study was supported by a grant from the Netherlands Asthma Foundation.

1 Connolly CK. Diurnal rhythms in airway obstruction. Br J Dis Chest 1979;73:357-66.

2 van Aalderen WMC, Postma DS, Koëter GH, Knol K. The effect of reduction of maintenance treatment on circadian variation in peak expiratory flow rate values in asthmatic children. Acta Paediatr Scand 1988;77:269-74.

3 Hetzel MR, Clark TJH. Comparison of normal and circadian rhythms in peak expiratory flow rate. Thorax 1980; 35:732-8.

4 Brown JK, Leff AR, Frey MJ, Reed BR, Lazarus SC, Shields $R$, Gold WN. Characterization of tracheo mast cell reactions in vivo. Inhibition by a beta adrenergic agonist. Am Rev Respir Dis 1982;126:842-8.

5 Kraan J, Koëter GH, van der Mark TW, Sluiter HJ, de.Vries $K$. Changes in bronchial hyperreactivity induced by 4 weeks of treatment with anti-asthmatic drugs in patients with allergic asthma: a comparison between Budesonide with allergic asthma: a comparison between Budesonide

6 van Aalderen WMC, Postma DS, Koëter GH, Knol K. Circadian change in bronchial responsiveness and airflow obstruction in asthmatic children. Thorax 1989;44:803-7.

7 Kjellman NIM. Predictive value of high IgE levels in children. Acta Paediatr Scand 1976;65:465-71.

8 Zapletal A, Samanek M, Paul T. Lung function in children and adolescents. Methods, reference values. In: Zapletal A, ed. Progress in respiration research. Vol 22 . Basle: A, ed. Progress in respir.

9 Westerink BHC, Bosker. FJ, O'Hanlon JS. Use of alumina, Sephadex G10, ion exchange columns to purify samples for the determination of epinephrine, norepinephrine, dopamine, homovanillic acid, and 5-hydroxy-indoleacetic acid in urine. Clin Chem 1982;69:251-8. 
10 Keyzer JJ, Wolthers BG, Muskiet FAJ, Kauffman HF, Groen A. Determination of $N^{*}$-methylhistamine in plasma and urine isotope dilution mass fragmentography. Clin Chim Acta 1981;113:165-77.

11 Keyzer JJ, Wolthers BG, Breukelman H, van der Slik W, de Vries K. Determination of $N^{i}$-methylhistamine in urine by gas chromatography using nitrogen-phosphorus detection. J Chromatogr 1983;275:261-9.

12 Kallenbach JM, Webster T, Dowdeswell R, Reinach SG, Scott Millar RN, Zwi S. Heart rate control in asthma. Evidence of parasympathetic overactivity. Chest 1985;87: 644-8.

13 Bennett T, Farquhar IK, Hosking DJ, Hampton JR. Assessment of methods for estimating autonomic control of the heart in patients with diabetes mellitus. Diabetes 1978; 27:1167-74.

14 Ewing DJ, Borsey DQ, Bellavere F, Clark BF. Cardiac autonomic neuropathy in diabetes: comparison of measures of R-R interval variation. Diabetologia 1981; 21:18-24.

15 Barnes P, FitzGerald G, Brown M, Dollery C. Nocturnal asthma and changes in circulating epinephrine, histamine and cortisol. N Engl J Med 1980;303:263-7.

16 Postma DS, Keyzer JJ, Koëter GH, Sluiter HJ, de Vries K. Influence of parasympathetic and sympathetic nervous system on nocturnal bronchial obstruction. Clin $\mathrm{Sci}$ 1985;69:251-8.17.

17 Bianco S, Fumagalli G, Ghiringhelli G, Allegra L. Influence and use of the employ of disodium cromoglycate "DSCG" on circadian rhythms in pulmonary mechanics. Revue de L'Institut D'Hygiene des Mines 1973;28:11-21.

18 Hetzel MR, Clark TJH, Gillam SJ, Isaac P, Perkins M. Is sodium cromoglycate effective in nocturnal asthma? Thorax 1985;40:793-4.

19 Flint KC, Leung KBP, Hudspith BN, Brostoff J, Pearce J, Johnson NM. Bronchoalveolar mast cells in extrinsic asthma; a mechanism for the initiation of antigen specific bronchoconstriction. BMJ 1985;291:923-6.

20 Szentivanyi $A$. The $\beta$-adrenergic theory of the atopic abnormality in bronchial asthma. J Allergy 1968;42: 204-32.

21 Morrison JFJ, Pearson SB, Dean HG. Parasympathetic nervous system in nocturnal asthma. BMJ 1988;296: 1427-9.

22 Hetzel MR, Clark TJH. Does sleep cause nocturnal asthma? Thorax 1979;34:749-54.

23 Catterall JR, Rhind GB, Steward IC, Whyte KF, Shapiro $\mathrm{CM}$, Douglas NJ. Sleep deprivation on overnight bronchoconstriction in nocturnal asthma. Thorax 1986; 41:676-80. 